\title{
Transfer of $\beta$-hydroxy- $\beta$-methylbutyrate from sows to their offspring and its impact on muscle fiber type transformation and performance in pigs
}

Haifeng Wan ${ }^{\dagger}$, Jiatao Zhu ${ }^{\dagger}$, Caimei Wu ${ }^{\dagger}$, Pan Zhou, Yong Shen, Yan Lin, Shengyu Xu, Lianqiang Che, Bin Feng, Jian Li, Zhengfeng Fang and De Wu

\begin{abstract}
Background: Previous studies suggested that supplementation of lactating sows with $\beta$-hydroxy- $\beta$-methylbutyrate (HMB) could improve the performance of weaning pigs, but there were little information in the muscle fiber type transformation of the offspring and the subsequent performance in pigs from weaning through finishing in response to maternal HMB consumption. The purpose of this study was to determine the effect of supplementing lactating sows with $\mathrm{HMB}$ on skeletal muscle fiber type transformation and growth of the offspring during $\mathrm{d} 28$ and 180 after birth. A total of 20 sows according to their body weight were divided into the control $(C O N, n=10)$ or $\mathrm{HMB}$ groups ( $\mathrm{HMB}, n=10)$. Sows in the HMB group were supplemented with $\beta$-hydroxy- $\beta$-methylbutyrate calcium (HMB-Ca) $2 \mathrm{~g} / \mathrm{kg}$ feed during d 1 to 27 of lactation. After weaning, 48 mixed sex piglets were blocked by sow treatment and fed standard diets for post-weaning, growing, finishing periods. Growth performance was recorded during d 28 to 180 after birth. Pigs were slaughtered on d 28 ( $n=6 /$ treatment) and 180 ( $n=6 /$ treatment) postnatal, and the longissimus dorsi (LD) was collected, respectively.
\end{abstract}

Results: The HMB-fed sows during lactation showed increased HMB concentration $(P<0.05)$ in milk and LD of weaning piglets $(P<0.05)$. In addition, offsprings in $\mathrm{HMB}$ group had a higher finishing BW and lean percentage than did pigs in CON group $(P<0.05)$, meanwhile, compared with pigs from sows fed the CON diet, pigs from sows fed HMB diet showed higher type II muscle fiber cross-sectional area (CSA), elevated myosin heavy chain (MyHC) $/ / b$ and Sox6 mRNA, and fast-MyHC protein levels in LD $(P<0.05)$.

Conclusions: HMB supplemented to sow diets throughout lactation increases the levels of HMB in maternal milk and skeletal muscle of pigs during d 28 after birth and promotes subsequent performance of pigs between d 28 and 180 of age by enhancing glycolytic muscle fiber transformation.

Keywords: $\beta$-hydroxy- $\beta$-methylbutyrate, Lactating sow, Muscle fiber, Offspring, Performance

\footnotetext{
* Correspondence: sow_nutrition@sina.com

${ }^{\dagger}$ Equal contributors

Institute of Animal Nutrition, Sichuan Agricultural University, No. 211, Huimin

Road, Wenjiang District, Chengdu 611130, Sichuan, People's Republic of

China
} 


\section{Background}

It has been suggested that establishing sufficient skeletal muscle is essential for lasting metabolic health [1]. Growing evidence has further indicated that maternal nutrition during lactation plays an important role in postnatal skeletal muscle development and growth of the offspring [2]. Skeletal muscle satellite cells provide myonuclei with muscle fibers and fuse with them, leading to muscle fiber hypertrophy. In addition, the transitions in myosin heavy chain isoforms are accelerated at postnatal 2 to $3 \mathrm{wk}$ and muscle fiber type is quite vulnerable to various stimuli, which might affect subsequent growth and health [3]. Research has suggested that a high-protein/ low-carbohydrate diet fed to mice during lactation impeded skeletal muscle growth in offspring and caused a transient shift towards oxidative versus glycolytic muscle metabolism [4]. Meanwhile, Lefaucheur et al. [5] reported that early postnatal under-nutrition of piglets reduced the glycolytic capacity of skeletal muscle, which was reflected a delay in muscle maturation. In addition, studies have shown that insulin resistance correlates with skeletal muscle fiber distribution and a decreased percentage of slow oxidative type I fibers [6, 7]. Conde-Aguilera et al. also found that feeding a diet with $30 \%$ deficient in total sulfur amino acid to piglets during $10 \mathrm{~d}$ after weaning decreased fast-twitch muscle growth and glycolytic metabolism [8]. As a result, it is of great interest that maternal nutrition interventions during lactation are being developed to increase or maintain skeletal muscle mass, which might have a lasting impact on future performance.

Studies have suggested that leucine could activate the mammalian target of rapamycin (mTOR) to promote skeletal muscle protein synthesis in pigs [9]. Moreover, $\beta$-hydroxy- $\beta$-methylbutyrate (HMB) is a metabolite of leucine, which has also similar effects with leucine in promoting skeletal muscle growth [10]. Moore et al. [11] showed that when the early post-hatch poult was fed with $0.1 \% \beta$ hydroxy- $\beta$-methylbutyrate calcium (HMB-Ca), HMB may improve muscle development via an increase in myogenic satellite cell mitotic activity. Meanwhile, previous studies have also shown that HMB could stimulate satellite cell proliferation and differentiation $[12,13]$, and dietary HMB supplementation to piglets during early postnatal period promoted skeletal muscle fiber development [14]. However, limited research existed evaluating the impact of maternal HMB consumption during lactation on skeletal muscle development of the offspring. Therefore, the study was to assess the effect of feeding HMB to sows during lactation on muscle fiber type transformation and performance of the offspring during d 28 and 180 after birth.

\section{Methods}

All procedure including use and treatment of animals was in accordance with guidelines set by the Animal
Care and Use Committee of Sichuan Agricultural University. The calcium salt (monohydrate) of $\beta$-hydroxy- $\beta$-methylbutyrate (purity 93\%), was purchased from Jiangyin Sanyi Chemical Co., Ltd., (Jiangsu, China).

\section{Animal, diets and treatments}

A total of 20 Landrace $\times$ Yorkshire (the third parity) pregnant sows with similar body weight $(252.9 \pm 3.6 \mathrm{~kg})$ were used in the experiment. At d 110 of gestation, sows were moved to farrowing room and were also individually penned $(2.06 \mathrm{~m} \times 1.50 \mathrm{~m})$, and all sows were randomly assigned to control (CON, $n=10$ ) or experimental groups (HMB, $n=10$ ) according to their body weights. All sows were fed $2.60 \mathrm{~kg} / \mathrm{d}$ gestation diet from d 110 of gestation to parturition. After farrowing, the CON sows were fed a basal lactation diet (Table 1), and the sows in the HMB group were fed basal lactation diet supplemented with $2.0 \mathrm{~g} / \mathrm{kg}$ of HMB-Ca. The feed level was progressively

Table 1 Composition and nutrient levels of the basal diets for sows during lactation (as-fed basis) ${ }^{a}$

\begin{tabular}{|c|c|}
\hline Ingredient & Percent \\
\hline Corn & 63.50 \\
\hline Soybean meal & 23.00 \\
\hline Fish meal & 3.00 \\
\hline Wheat bran & 5.00 \\
\hline Soybean oil & 2.50 \\
\hline L-Lysine $\mathrm{HCl}$ (98\%) & 0.08 \\
\hline Limestone & 0.87 \\
\hline Dicalcium phosphate & 1.00 \\
\hline Choline chloride (50\%) & 0.15 \\
\hline Salt & 0.40 \\
\hline Vitamin and mineral premix ${ }^{b}$ & 0.50 \\
\hline \multicolumn{2}{|l|}{ Calculated nutrient levels ${ }^{c}$} \\
\hline$C P, \%^{d}$ & 17.90 \\
\hline$M E, M J / k^{d}$ & 13.65 \\
\hline $\mathrm{Ca}, \%^{\mathrm{d}}$ & 0.78 \\
\hline $\mathrm{TP}, \%^{\mathrm{d}}$ & 0.63 \\
\hline$A P, \%^{d}$ & 0.41 \\
\hline Total Lys, \% & 1.02 \\
\hline Total Met + Cys, $\%^{d}$ & 0.58 \\
\hline Total Leu, \% ${ }^{\mathrm{e}}$ & 1.51 \\
\hline \multicolumn{2}{|c|}{ 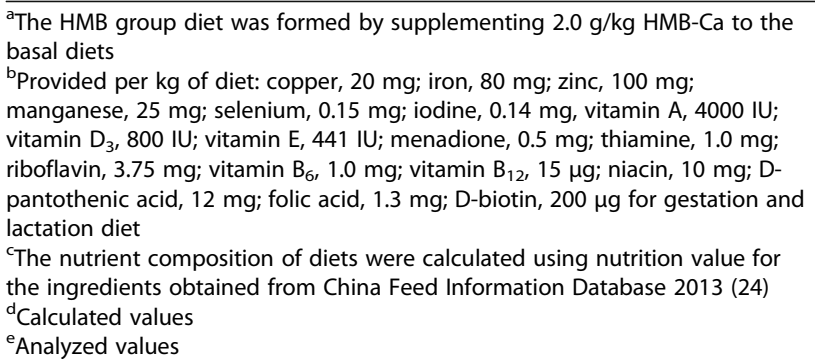 } \\
\hline
\end{tabular}


increased during the first $5 \mathrm{~d}$ of lactation, and was allowed free access to feed during the $\mathrm{d} 6$ of lactation to weaning, and sow feed intake was record daily during lactation. In addition, each pig from each litter was individually weighted at birth. In addition, the litter size was standardized to 10 piglets per litter by cross-fostering within the treatment group beyond $24 \mathrm{~h}$ after birth, and piglets had free access to water and creep feed was not provided to piglets at any point during the lactation period. Male piglets were castrated on $\mathrm{d} 7$ after birth and all piglets were weaned at $28 \mathrm{~d}$ of age.

At weaning (d 28 of lactation), due to housing restriction, a total of 48 mixed sex pigs ( 24 barrows and 24 gilts, $n=24$ /treatment) from ten randomly litters per treatment approaching an average weight were selected and blocked according to maternal treatment, and were moved to 12 nursery pen $(1.46 \mathrm{~m} \times 1.30 \mathrm{~m}$ per pen, 2 barrows and 2 gilts per pen) until $d 66$ of age. At the $d$
67 of age, these pigs were moved to 12 grow-finish pens ( $2.03 \mathrm{~m} \times 1.90 \mathrm{~m}$ per pen, 2 barrows and 2 gilts per pen) until the d 180 of age. In the whole experimental period, all the pigs had free access to water and were fed ad libitum, and they were phased-fed standard nursery and growing-finishing diets twice daily until d 180 after birth (Table 2).

\section{Performance measurement and sample collection}

For the growth performance study, pigs were individually weighted at birth and postnatal d 28, 66, 108, 150 and 180 , respectively. The average daily gain (ADG) was calculated as (weight change/number of days) $\times 1000$. Average daily feed intake was obtained from all pens in the nursery period and growing-finishing period, and the Feed/Gain $(F / G)$ was calculated as the average daily feed intake (ADFI) /ADG. Plasma samples $(10 \mathrm{~mL})$ were also collected from the jugular vein of six piglets closest

Table 2 Composition and nutrient levels of the basal diets for the offspring (as-fed basis)

\begin{tabular}{|c|c|c|c|c|}
\hline & \multicolumn{4}{|c|}{ Growth stage } \\
\hline & D 28 to 66 & D 67 to 108 & D 109 to 150 & D 151 to 180 \\
\hline \multicolumn{5}{|l|}{ Ingredient, \% } \\
\hline Corn & 59.6 & 64.3 & 70.4 & 75.3 \\
\hline Soybean meal & 18.0 & 24.0 & 22.0 & 16.0 \\
\hline Fish meal & 3.0 & 2.0 & - & - \\
\hline Full fat soybean & 5.0 & - & - & - \\
\hline Wheat bran & - & 5.0 & 4.0 & 5.0 \\
\hline Whey powder & 8.0 & - & - & - \\
\hline Sucrose & 2.0 & - & - & - \\
\hline L-Lysine HCl (98\%) & - & 0.26 & 0.28 & 0.27 \\
\hline D,L-Methionine (99\%) & - & 0.08 & 0.06 & 0.06 \\
\hline L-Threonine (98.5\%) & - & 0.06 & 0.06 & 0.06 \\
\hline Limestone & 0.50 & 0.60 & 0.80 & 0.85 \\
\hline Dicalcium phosphate & 1.00 & 1.30 & 1.00 & 1.06 \\
\hline Choline chloride (50\%) & 0.10 & 0.10 & 0.10 & 0.10 \\
\hline Salt & 0.30 & 0.30 & 0.30 & 0.30 \\
\hline Soybean oil & 1.00 & 1.00 & - & - \\
\hline Vitamin and mineral premix $x^{a}$ & 1.50 & 1.00 & 1.00 & 1.00 \\
\hline \multicolumn{5}{|l|}{ Calculated nutrient levels ${ }^{\mathrm{b}}$} \\
\hline $\mathrm{ME}, \mathrm{MJ} / \mathrm{kg}$ & 13.39 & 13.35 & 13.19 & 13.15 \\
\hline$C P, \%$ & 18.0 & 17.7 & 15.9 & 13.8 \\
\hline $\mathrm{Ca}, \%$ & 0.72 & 0.71 & 0.63 & 0.63 \\
\hline $\mathrm{TP}, \%$ & 0.60 & 0.67 & 0.55 & 0.54 \\
\hline Total Lys, \% & 1.35 & 1.12 & 0.97 & 0.84 \\
\hline
\end{tabular}

${ }^{\mathrm{a}}$ Provided per $\mathrm{kg}$ of diet for piglets from d 28 to 66 of age: iron, $100 \mathrm{mg}$; copper, $6 \mathrm{mg}$; zinc, $100 \mathrm{mg}$; manganese, $4 \mathrm{mg} ;$ selenium, $0.30 \mathrm{mg}$; and iodine, $0.14 \mathrm{mg}$; vitamin $A, 2,200 \mathrm{IU}$; vitamin $D_{3}, 220 \mathrm{IU}$; vitamin $\mathrm{E}, 16$; menadione, $0.5 \mathrm{mg}$; thiamine, $1.5 \mathrm{mg}$; riboflavin, $4.0 \mathrm{mg}$; vitamin $\mathrm{B}_{6}, 7.0 \mathrm{mg}$; vitamin $\mathrm{B}_{12}, 20 \mu \mathrm{g}$; niacin, 30 mg; D-pantothenic acid, 12 mg; folic acid, $0.3 \mathrm{mg}$; and D-biotin, $80 \mu \mathrm{g}$ Provided per kg of diet for pigs from d 67 to 180 of age: iron, $60 \mathrm{mg}$; copper, $6 \mathrm{mg}$; zinc, $60 \mathrm{mg}$; manganese, $4 \mathrm{mg}$; selenium, $0.30 \mathrm{mg}$; and iodine, $0.14 \mathrm{mg}$; vitamin $\mathrm{A}, 1,300 \mathrm{IU}$; vitamin $\mathrm{D}_{3}, 150 \mathrm{IU}$; vitamin $\mathrm{E}$, $11 \mathrm{IU}$; menadione, $0.5 \mathrm{mg}$; thiamine, $1.0 \mathrm{mg}$; riboflavin, $3.0 \mathrm{mg}$; vitamin $\mathrm{B}_{6}, 1.0 \mathrm{mg}$; vitamin $\mathrm{B}_{12}, 10 \mu \mathrm{g}$; niacin, $30 \mathrm{mg}$; D-pantothenic acid, $8 \mathrm{mg}$; folic acid, $0.3 \mathrm{mg}$; D-biotin, $50 \mu \mathrm{g}$

${ }^{\mathrm{b}}$ The nutrient composition of diets were calculated using nutrition value for the ingredients obtained from China Feed Information Database 2013 (24) 
to the average body weight of each treatment on d 28 of lactation. Samples were collected in heparinized tubes kept on the ice and centrifuged at 2,550 $\times$ g for $10 \mathrm{~min}$ at $4{ }^{\circ} \mathrm{C}$. Milk samples $(30 \mathrm{~mL})$ were collected from all functional glands of sows at d 28 of lactation by injecting $1 \mathrm{mg}$ oxytocin into the ear vein. The plasma supernatant and milk samples were refrigerated at $-20{ }^{\circ} \mathrm{C}$ immediately prior to subsequent analysis. At d 28 and 180 after birth, a total of 24 pigs (one castrated male pig with mean body weight per pen) were slaughtered after overnight fasting by electrical stunning followed by exsanguination, according to the method of Refeldt et al. [4]. After slaughter, the abdomen was opened, and the entire intestine was rapidly removed. Then, all samples for mRNA, histological and biochemical analyses were collected as quickly as possible. Longissimus dorsi (LD) samples from the left half of the carcass were dissected at the level of the $12^{\text {th }} / 13^{\text {th }}$ ribs for pigs during $d 28$ and 180 after birth, as previously described by Cerisuelo et al. [15], and were rapidly frozen in liquid nitrogen and stored at $-80{ }^{\circ} \mathrm{C}$ for subsequent RNA and biochemical analyses. The LD at the level of the $11^{\text {th }} / 12^{\text {th }}$ ribs was excised and stored in liquid nitrogen for subsequent muscle morphological assessment. The right half of the carcass was dissected into primary cuts, such as the loin, neck and ham, which were further manually separated into lean meat, subcutaneous fat, bones, and skin for pigs at d 180 after birth, as described by Rehfeldt et al. [4].

\section{Milk and muscle HMB determination}

Milk and muscle tissue samples were measured for HMB content by a modification of the plasma and milk analysis method previously described by Deshpande et al. [16] and Ehling et al. [17]. Briefly, acidified muscle tissue homogenates were extracted with methyl-t-butyl ether for $2 \mathrm{~h}$, and $a$-hydroxy-a-methylbutyric acid (Sigma H40009; Sigma-Aldrich, Saint Louis, MO, USA) was used as an internal standard. The extracting solution was centrifuged at $12,000 \times g$ and $4{ }^{\circ} \mathrm{C}$ for $5 \mathrm{~min}$. Then, the supernatant was transferred to a clean test tube and evaporated to dryness by nitrogen flushing at $40{ }^{\circ} \mathrm{C}$. After drying, 1 and $4 \mathrm{~mL}$ of $0.10 \mathrm{~mol} / \mathrm{L} \mathrm{HCl}$ in $90 / 10$ (v/ v) water-acetonitrile were added the same test tube for milk and muscle sample, respectively. After a brief vortex mixing, the mixture was passed through an OASIS ${ }^{\bullet}$ MCX cartridge $(60 \mathrm{mg})$ and the eluate was collected for the muscle sample, and this step was omitted for milk sample. The HMB content was analysed via highperformance liquid chromatography with tandem mass spectrometry (LC-MS/MS, Agilent, USA). The recovery intra-day and inter-day are all > 85 and $70 \%$ for sow milk and piglet skeletal muscle, respectively, and the detectable minimum amount of HMB in the sow milk and piglet skeletal muscle were $0.02 \mu \mathrm{mol} / \mathrm{L}$ or $0.02 \mathrm{nmol} / \mathrm{g}$.
Biochemical analyses and amino acid content analysis Plasma insulin concentration was analyzed using a porcine insulin RIA kit (Tianjin Jiuding Medical Biological Engineering Co., LTD, Tianjin, China), and the detection limit of plasma insulin was $2 \mu \mathrm{U} / \mathrm{mL}$. Plasma glucose and urea levels were conducted by using specific assay kits (Nanjing Jiancheng Bioengineering Institute, Nanjing, China) according to the manufacturer's instructions, moreover, the detection range were $0-28 \mathrm{mmol} / \mathrm{L}$ and 0.03-19 $\mathrm{mmol} / \mathrm{L}$ for plasma glucose and urea, respectively. Plasma free amino acids content were determined according to the method as described by Li et al. [18], and briefly, $300 \mu \mathrm{L}$ of plasma sample and $900 \mu \mathrm{L}$ of $10 \%$ sulfosalicylic acid were mixed well and centrifuged at $12,000 \times \mathrm{g}$ and $4{ }^{\circ} \mathrm{C}$ for $15 \mathrm{~min}$. Then the supernatant fluid was filtered through a $0.22-\mu \mathrm{m}$-pore-size PTFE syringe filter (Millpore) into a 2-mL auto-sampler vial and determined for amino acid level by an L8800 high-speed analyzer (Hitachi, Tokyo, Japan) for the amino acid. Amino acid standard solutions type B and AN-II (Wako Pure Chemical Industries, Ltd., Osaka, Japan) were used for calibration.

\section{Cross-sectional area and total number of muscle fiber determination}

For histological analyses of muscle fiber, frozen muscle samples were equilibrated to $-25{ }^{\circ} \mathrm{C}$. Then transverse serial section $(10 \mu \mathrm{m})$ was cut in a cryostat at $-20{ }^{\circ} \mathrm{C}$ and subsequently mounted on glass microscopic slides. These sections were then stained with acid-preincubated ATPase treatment at $\mathrm{pH} 4.20$ and subsequent alkaline $(\mathrm{pH}=9.40)$ treatment to evaluate muscle fiber morphology using a modification of the method of Guth et al. [19]. All sections were photographed using a digital microscope (Nikon), and muscle fibers were counted over 5 randomly selected fields of known size (1.01 mm $\mathrm{mm}^{2}, 200$ to 300 fibers). The total number of fibers was calculated by multiplication of the number of fibers per centimeter ${ }^{2}$ with the loin meat area (LMA), and the mean muscle fiber cross-sectional area (CSA) in the united area was measured by Image-Pro Plus 6.0 software (Media Cybernetics, Bethesda, MD).

\section{RNA isolation, CDNA synthesis and real-time PCR}

Approximately $50 \mathrm{mg}$ of muscle samples were crushed and total RNA was extracted using RNAiso Plus reagent (TaKaRa). The integrity of RNA was estimated by electrophoresis on a $1 \%$ agarose gel stained with ethidium bromide and the purity of total RNA was verified using a Nanovue $^{\mathrm{TM}}$ Plus Spectrophotometer (GE Healthcare, $\mathrm{UK})$ at 260 and $280 \mathrm{~nm}$. The $\mathrm{OD}_{260} / \mathrm{OD}_{280}$ ratios of the RNA samples were all between 1.8 and 2.0. Subsequently, reverse transcription was performed from $1 \mu \mathrm{g}$ of total RNA using the PrimeScript ${ }^{\mathrm{TM}}$ RT Reagent Kit 
(TaKaRa) according to the manufacturer's recommendations, and the reverse transcription products (cDNA) were stored at $-20{ }^{\circ} \mathrm{C}$ for relative quantification by PCR. Primers were designed by Primer Express 3.0 (Applied Biosystems, Foster, CA, USA) based on known sequence deposited in GenBank, and the detected genes of muscle samples included myogenic genes (Pax7, MRF4 and $M S T N$ ), protein synthesis and degradation factors (IGFI, mTOR, MAFbx and MuRF1), transcription factor (Sox6 and FoxO1), myosin heavy chain $(\mathrm{MyHC}$ ) isoform (slow/I, IIa, IIx and IIb), and the information of primers was presented in Table 3. Real-time-qPCR analysis was carried out using the SYBR Green method and the target genes were quantified using CFX manager V1.1 software (Bio-Rad Laboratories). The mixture $(10 \mu \mathrm{L})$ contained $5 \mu \mathrm{L} \mathrm{SYBR}^{\bullet}$ Premix Ex Taq ${ }^{\mathrm{TM}}$ II (TaKaRa), $1 \mu \mathrm{L}$ cDNA,
$0.5 \mu \mathrm{L}$ of each gene-specific primer, and $3 \mu \mathrm{L} \mathrm{ddH}_{2} \mathrm{O}$. All measurements were performed in triplicate. The thermal cycling conditions were follows: denaturation at $95{ }^{\circ} \mathrm{C}$ for $15 \mathrm{~s}$, followed by 40 cycles of denaturation at $95{ }^{\circ} \mathrm{C}$ for $5 \mathrm{~s}$ and annealing at $61.5{ }^{\circ} \mathrm{C}$ for $30 \mathrm{~s}$, and collection of fluorescent signals. The relative mRNA abundances of the target genes were calculated using the $2^{-\triangle \Delta C T}$ method, and glyceraldehyde-3-phosphate dehydrogenase (GAPDH) was used as a reference gene in this study. The mRNA level of each target gene for Con group was set to 1.0.

Tissue protein extraction and Western blot analysis Frozen LD samples were lysed, and the protein concentration was measured using a protein assay kit (Nanjing Jiancheng Bioengineering Institute, Nanjing, China) according

Table 3 The primer sequences of the target genes

\begin{tabular}{|c|c|c|c|}
\hline Target gene & Primer sequence ( $5^{\prime}$ to $3^{\prime}$ ) & Product size, bp & GenBank No. \\
\hline \multirow[t]{2}{*}{$\mathrm{MyHCl}$} & F: GTTTGCCAACTATGCTGGGG & 95 & NM_213855.1 \\
\hline & R: TGTGCAGAGCTGACACAGTC & & \\
\hline \multirow[t]{2}{*}{ MyHClla } & F: CTCTGAGTTCAGCAGCCATGA & 127 & NM_214136.1 \\
\hline & R: GATGTCTTGGCATCAAAGGGC & & \\
\hline \multirow[t]{2}{*}{ MyHCIIx } & F: TTGACTGGGCTGCCATCAAT & 111 & NM_001104951.1 \\
\hline & R: GCCTCAATGCGCTCCTITTC & & \\
\hline \multirow[t]{2}{*}{ MyHCllb } & F: GAGGTACATCTAGTGCCCT & 83 & NM_001123141.1 \\
\hline & R: GCAGCCTCCCCAAAAATAGC & & \\
\hline \multirow[t]{2}{*}{ Pax7 } & F: TGAAGGTCGGAGTGAACGGAT & 74 & NM_001206359.1 \\
\hline & R: CACTITGCCAGAGTTAAAAGCA & & \\
\hline \multirow[t]{2}{*}{ IGF-1 } & F: CACAGACGGGCATCGTGGAT & 90 & NM_214256.1 \\
\hline & R: ACTTGGCAGGCTTGAGGGGT & & \\
\hline \multirow[t]{2}{*}{ mTOR } & F: CATTGGAGATGGTTTGGTGA & 160 & XM_003127584.5 \\
\hline & R: ATGGGATGTGGCTTGTTTGA & & \\
\hline \multirow[t]{2}{*}{ MRF4 } & F: CCTTCGGTGCCTTTCTTCCAT & 88 & NM_001244672.1 \\
\hline & R: GAGTTATTTCTCCCCCACTTCC & & \\
\hline \multirow[t]{2}{*}{ MSTN } & F: TTACCTGTTTATGCTGATTGTTG & 194 & NM_214435.2 \\
\hline & R: TTTGCTAATGTTAGGAGCTGTTTC & & \\
\hline \multirow[t]{2}{*}{ FoxO1 } & F: TCAAGGATAAGGGCGACAGC & 95 & NM_214014.2 \\
\hline & R: AATGTCATTATGGGGAGGAGAGT & & \\
\hline \multirow[t]{2}{*}{ Sox6 } & F: CGGATTGGGGAGTATAAGCA & 159 & XM_01399454.1 \\
\hline & R: CATCTGAGGTGATGGTGTGG & & \\
\hline \multirow[t]{2}{*}{ MAFbX } & F: CCCTCTCATTCTGTCACCTTG & 104 & NM_001044588 \\
\hline & R: ATGTGCTCTCCCACCATAGC & & \\
\hline \multirow[t]{2}{*}{ MURF1 } & F: GCTGGATTGGAAGAAGATGTAT & 144 & NW_001184756 \\
\hline & R: AGGAAAGAATGTGGCAGTGTCT & & \\
\hline \multirow[t]{2}{*}{ GAPDH } & F: TGAAGGTCGGAGTGAACGGAT & 74 & NM_001206359.1 \\
\hline & R: CACTTTGCCAGAGTTAAAAGCA & & \\
\hline
\end{tabular}


to the manufacturer's instructions. Western blot analysis of fast-MyHC protein (anti-fast myosin skeletal heavy chain antibody, Abcam, ab91506, diluted 1: 5,000) was conducted according to a previous publication [20]. The relative expression of the target protein was normalized to GAPDH (bio-rich042, BMSX, diluted 1: 20,000) as an internal control. The band density of fast-MyHC was normalized to that of GAPDH and fast-MyHC protein content was presented as the fold change relative to the CON group.

\section{Statistical analysis}

For performance of fattening pigs, individual pen served as the experimental unit, and other data including skeletal muscle characteristics, plasma amino acid and metabolites, milk and muscle HMB levels, muscle fiber histological analyses, gene and protein expressions were analyzed with the individual pig as the experimental unit. For means separation, differences among the least square means of the $\mathrm{CON}$ vs. HMB treatments were compared using $t$-tests analysis. The results for mRNA level and fast-MyHC protein expression are presented as the least square mean and their SEM, and other results in tables are shown as the mean and pooled SEM. A difference was considered statistically significant when $P<0.05$, if the $P$-values were between 0.05 and 0.10 , the difference was considered a tendency.

\section{Results}

\section{Performance and skeletal muscle composition}

The results of sow feed intake during lactation was provided in Fig. 1. Sows in the HMB group had lower feed intake than those in the CON group $(P<0.05)$. The fattening pig performance body composition are presented in Tables 4 and 5 . The average feed intake (ADFI) of pigs during d 28 to 180 was not different between treatments. However, pigs from sows fed HMB diet during lactation exhibited higher final weight (+6.0\%, $P<0.05)$, ADG $(+6.4 \%, P<0.05)$, and had a decreased tendency in F/G $(-3.5 \%, P=0.069)$ than did pigs from sows fed the $\mathrm{CON}$ diet during postnatal d 28 to 180 . In addition, fattening pigs from sows fed HMB diets also showed superior carcass weight $(P<0.05)$ and lean meat percentage $(P=0.07)$ than did pigs from sows fed the $\mathrm{CON}$ diet.

\section{Milk and muscle HMB, plasma amino acid and metabolites concentrations}

As shown in Table 6, sows supplemented with HMB diet had an increased HMB concentration in milk at d 28 of lactation $(P<0.01)$ than sows fed with $C O N$ diet, with piglets from HMB-supplemented sows having an elevated HMB concentration $(P<0.01)$ of LD than those of their CON counterparts at $\mathrm{d} 28$ of age. In addition, in comparison with $\mathrm{CON}$ piglets, maternal $\mathrm{HMB}$ treatment increased plasma leucine $(P<0.05)$ and essential amino acid (EAA) contents $(P<0.05)$ of the piglets at $\mathrm{d} 28$ of age. Similarly, plasma glucose content exhibited an increased level $(P<0.05)$ for piglets from $\mathrm{HMB}$ than $\mathrm{CON}$ groups, Furthermore, there was an increased tendency in the plasma insulin content for piglets from sows supplemented HMB diet than those from sows supplemented CON diet $(P=0.078)$.

\section{Muscle fiber characteristics}

Data on the measures of CSA and numbers of muscle fiber in LD of fattening pigs are shown in Table 7. An

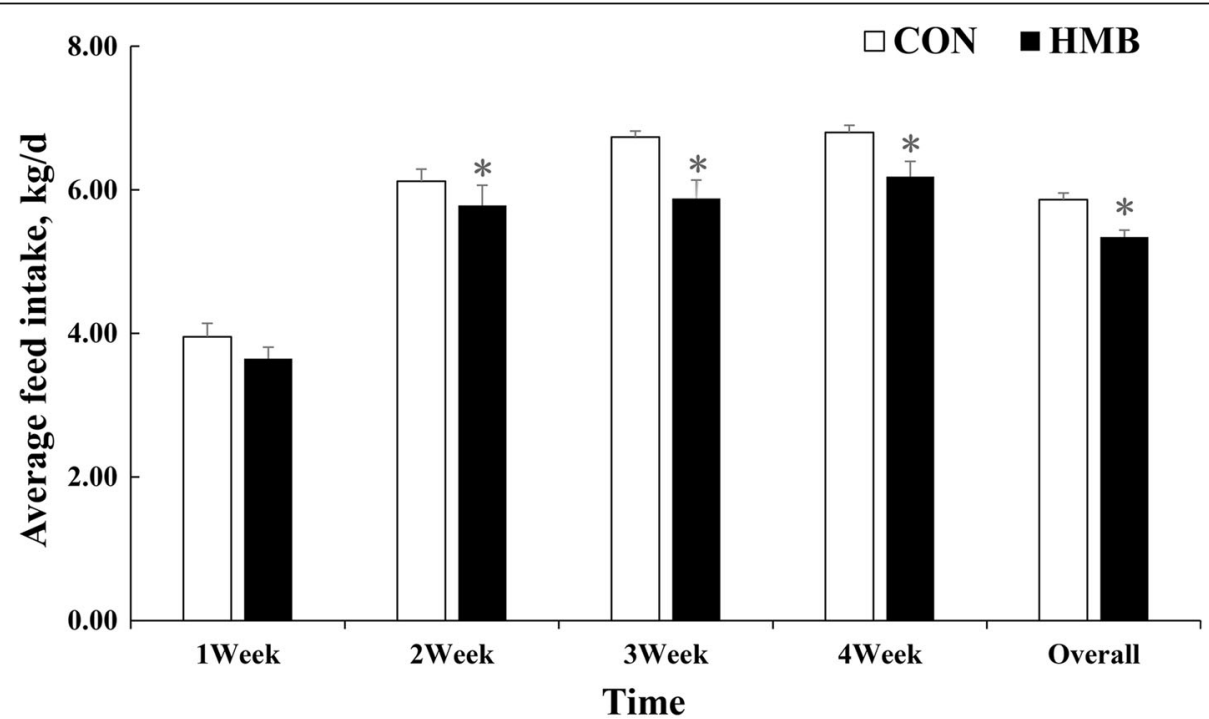

Fig. 1 Effects of dietary supplementation of HMB on average feed intake of sows during lactation. Values are means, with their standard errors represented by vertical bars $(n=10)$. ${ }^{*}$ Represents mean values between the two groups differ significantly at $P<0.05$. CON control; HMB $\beta$-hydroxy- $\beta$-methylbutyrate 
Table 4 Effects of feeding HMB to sows during lactation on performance of the offspring

\begin{tabular}{|c|c|c|c|c|}
\hline & CON & $\mathrm{HMB}$ & SEM & $P$ value \\
\hline Number of pigs on trial (n) & 24 & 24 & & \\
\hline \multicolumn{5}{|l|}{ Pig BW, kg } \\
\hline At birth & 1.41 & 1.42 & 0.07 & 0.887 \\
\hline D 28 & 7.65 & 7.81 & 0.32 & 0.670 \\
\hline D 66 & 22.6 & 22.9 & 0.5 & 0.677 \\
\hline D 108 & 47.6 & 49.4 & 1.1 & 0.293 \\
\hline D 150 & 79.8 & 83.9 & 1.4 & 0.080 \\
\hline D 180 & 105.7 & 112.0 & 1.8 & 0.041 \\
\hline \multicolumn{5}{|l|}{ Pig ADFl, g/d } \\
\hline D 28 to 66 & 586 & 579 & 24 & 0.836 \\
\hline D 67 to 108 & 1,087 & 1,158 & 29 & 0.122 \\
\hline D 109 to 150 & 2,187 & 2,250 & 64 & 0.505 \\
\hline D 151 to 180 & 3,048 & 3,071 & 83 & 0.845 \\
\hline Overall & 1,652 & 1,693 & 30 & 0.368 \\
\hline \multicolumn{5}{|l|}{ Pig ADG, g/d } \\
\hline D 28 to 66 & 394 & 398 & 13 & 0.828 \\
\hline D 67 to 108 & 588 & 631 & 19 & 0.153 \\
\hline D 109 to 150 & 773 & 820 & 27 & 0.247 \\
\hline D 151 to 180 & 864 & 939 & 40 & 0.226 \\
\hline Overall & 645 & 686 & 11 & 0.031 \\
\hline \multicolumn{5}{|l|}{$F / G$} \\
\hline D 28 to 66 & 1.49 & 1.45 & 0.03 & 0.457 \\
\hline D 67 to 108 & 1.85 & 1.84 & 0.03 & 0.720 \\
\hline D 109 to 150 & 2.83 & 2.74 & 0.05 & 0.200 \\
\hline D 151 to 180 & 3.56 & 3.28 & 0.15 & 0.232 \\
\hline Overall & 2.56 & 2.47 & 0.03 & 0.069 \\
\hline
\end{tabular}

$A D G$ average daily gain, $B W$ body weight, $A D F I$ average daily feed intake, $C O N$ control, $H M B$ B-hydroxy- $\beta$-methylbutyrate

increased tendency in the loin meat area (LMA) of LD was observed in fattening pigs from sows fed HMB diet compared with fattening pigs from sows fed the CON diet $(P=0.069)$. Similarly, higher type II muscle fiber CSA $(P<0.05)$ was discovered in offspring from sows fed $\mathrm{HMB}$ diet during lactation than in those from sows fed the CON diet, and pigs the HMB group had also an elevated tendency in the total mean myofiber CSA than those in the CON group $(P=0.065)$.

\section{Gene and protein expression}

According to Figs. 2, 3, 4 and 5, maternal HMB treatment during lactation induced increased $m T O R$ and Sox6 mRNA levels in LD of the offspring at d 28 of age $(P<0.05)$. Meanwhile, no significant effects were observed in of mRNA levels of MAFbx and MuRF1 in skeletal muscle of weaning piglets between treatments $(P>0.05)$. However, higher mRNA levels of
Table 5 Effects of feeding HMB to sows during lactation on skeletal muscle composition of the offspring

\begin{tabular}{lllll}
\hline & CON & HMB & SEM $^{\text {a }}$ & $P$ value \\
\hline $\begin{array}{l}\text { Weaning pigs } \\
\text { Body weight, kg }\end{array}$ & 7.83 & 7.98 & 0.27 & 0.705 \\
LD weight, g & 127.2 & 130.7 & 9.0 & 0.792 \\
$\begin{array}{l}\text { Finishing pigs } \\
\text { Body weight, kg }\end{array}$ & 106.8 & 114.0 & 1.2 & 0.002 \\
Carcass weight, kg & 77.8 & 83.8 & 0.9 & 0.001 \\
LD weight, kg & 3.02 & 3.27 & 0.09 & 0.065 \\
Lean meat, \% & 63.05 & 66.25 & 1.09 & 0.067 \\
Bone, \% & 10.67 & 10.66 & 0.45 & 0.983 \\
SCAT, \% & 20.01 & 16.21 & 1.19 & 0.051 \\
Skin, \% & 6.27 & 6.88 & 0.23 & 0.100 \\
\hline $\begin{array}{l}\text { LD longissimus dorsi, SCAT subcutaneous adipose tissue, CON control, } \\
\text { HMB } \beta \text {-hydroxy- } \beta \text {-methylbutyrate } \\
\text { aPooled standard error of the mean ( } n=6 / \text { treatment) }\end{array}$
\end{tabular}

$M y H C-I I b$ were observed in LD of offspring in $\mathrm{HMB}$ group than those in the $\mathrm{CON}$ group during weaning and finishing stages $(P<0.05)$. In addition, weaning pigs in $\mathrm{HMB}$ group had an increased tendency in mRNA rate of $M y H C-I I b / M y H C-I$ of LD than those in the CON group $(P=0.073)$. Similarly, compared with those in pigs in the CON group, pigs in $\mathrm{HMB}$ group exhibited higher the fast-MyHC protein levels in LD of the pigs at weaning and finishing stages $(P<0.05)$.

\section{Discussion}

The first aim of the present study was to investigate the effects of maternal HMB consumption during lactation

Table 6 Effects of feeding HMB to lactating sows on HMB and amino acid metabolism in piglets during d 28 of lactation

\begin{tabular}{lllll}
\hline & CON & HMB & SEM $^{a}$ & $P$ value \\
\hline HMB level & & & & \\
Maternal milk, $\mu \mathrm{mol} / \mathrm{L}$ & 0.42 & 10.50 & 0.01 & $<0.001$ \\
Piglet' LD, nmol/g tissue & 6.04 & 7.51 & 0.33 & 0.025 \\
Plasma metabolite & & & & \\
Insulin, $\mu \mathrm{U} / \mathrm{mL}$ & 20.98 & 23.98 & 1.05 & 0.078 \\
Glucose, $\mathrm{mmol} / \mathrm{L}$ & 7.71 & 9.77 & 0.46 & 0.029 \\
Urea, $\mathrm{mmol} / \mathrm{L}$ & 4.79 & 4.40 & 0.34 & 0.860 \\
Leucine, $\mathrm{nmol} / \mathrm{mL}$ & 155.6 & 227.7 & 20.8 & 0.044 \\
BCAA, $\mathrm{nmol} / \mathrm{mL}$ & 516.8 & 561.2 & 37.8 & 0.437 \\
EAA, nmol/mL & 1,449 & 2,521 & 92 & 0.002 \\
NEAA, nmol/mL & 2,389 & 2,690 & 182 & 0.319 \\
\hline
\end{tabular}

$L D$ longissimus dorsi, $B C A A$ branched-chain amino acids, $E A A$ essential amino acid, NEAA nonessential amino acids, CON control,

$H M B \beta$-hydroxy- $\beta$-methylbutyrate

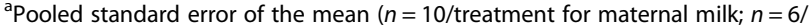
treatment for piglet's LD and plasma metabolite) 
Table 7 Effects of feeding HMB to lactating sows on muscle fiber characteristics of fattening pigs

\begin{tabular}{lllll}
\hline & CON & HMB & SEM $^{\mathrm{a}}$ & $P$ value \\
\hline LMA $\mathrm{cm}^{2}$ & 75.30 & 82.15 & 2.38 & 0.069 \\
Total number of muscle fiber, $\times 10^{3}$ & 1013 & 1018 & 42 & 0.935 \\
Mean myofiber CSA, $\mathrm{Mm}^{2}$ & & & & \\
Total & 3,615 & 4,268 & 183 & 0.065 \\
Type I & 2,732 & 3,203 & 213 & 0.169 \\
Type II & 3,719 & 4,774 & 252 & 0.025
\end{tabular}

LMA loin meat area, CSA cross sectional area, CON control, $H M B \beta$-hydroxy- $\beta$-methylbutyrate

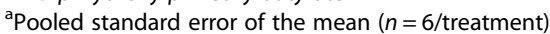

on performance and skeletal muscle characteristics of the offspring at weaning (d 28 after birth). It has established that maternal nutrition during lactation has previously been reported as one of the important factors affecting the growth of weaning pigs [21]. Given that pig performance was, to a great extent, influenced by birth BW, therefore, piglets with similar birth BW were selected and used in this experiment for $\mathrm{CON}$ and $\mathrm{HMB}$ groups, respectively. However, in the current trial, we found that maternal HMB treatment did not affect the BW of pigs at weaning, which disagreed with the findings of Nissen et al. [22], who reported that piglets from sows fed total HMB-Ca level of $2.0 \mathrm{~g} / \mathrm{d}$ from d 108 of gestation to d 21 of lactation had higher weaning BW compared with those from sows fed the CON diet, and the discrepancy are likely related to the higher dosage $(10.6 \mathrm{~g} / \mathrm{d})$ by multiplying dietary HMB level $(2 \mathrm{~g} / \mathrm{kg})$ by average feed intake of sows $(5.3 \mathrm{~kg} / \mathrm{d})$ during $\mathrm{d} 1$ to 27 of lactation in this study compared with the used dosage $(2 \mathrm{~g} / \mathrm{d})$ in previous study by Nissen et al. [22]. In addition, we found that dietary supplementation of higher level of HMB significantly reduced feed intake of sows during lactation (Fig. 1), which might be the important proof leading to the non-difference in BW of piglets at weaning. But till now it has not been demonstrated in the reduced feed intake of sows fed HMB, and research in the rat has shown that dietary HMB supplementation could impair insulin resistance and increase plasma non-essential fatty acid level [23], which could lead to the decreased feed intake during lactation, and the underlying mechanism of which remains to be explained further. However, studies have suggested that neonatal pigs have great growth potential in the immediate neonatal period, especially in terms of skeletal muscle growth, which is dependent on maternal milk intake and quality [24] and the increased milk production is associated with an increased lactation feeding level $[25,26]$, therefore, lower feed intake of sows during lactation might affect to some extent piglet growth in this study.

However, we found that feeding HMB to sows during lactation increased HMB level in maternal milk and LD of piglets in this study, which is consistent with the result of Nissen et al. [22] and Michelle et al. [27]. Meanwhile, higher plasma leucine, glucose, and insulin levels were observed in offspring in the HMB group, which is accordance with the results of Tatara et al. [28] and Wan et al. [14], and HMB could increase plasma amino acid and glucose levels of pigs $[14,28]$. In this respect, insulin, glucose and amino acid were the important anabolic promoters affecting skeletal muscle protein synthesis [24], moreover, no difference were observed in mRNA expressions of MuRF1 and MAFbx, which also provided the further evidence of the similar protein degradation in skeletal muscle of pigs between treatments. On the contrary, the increased mTOR mRNA expression was observed in the skeletal muscle of piglets in the HMB group. Therefore, these results suggested that

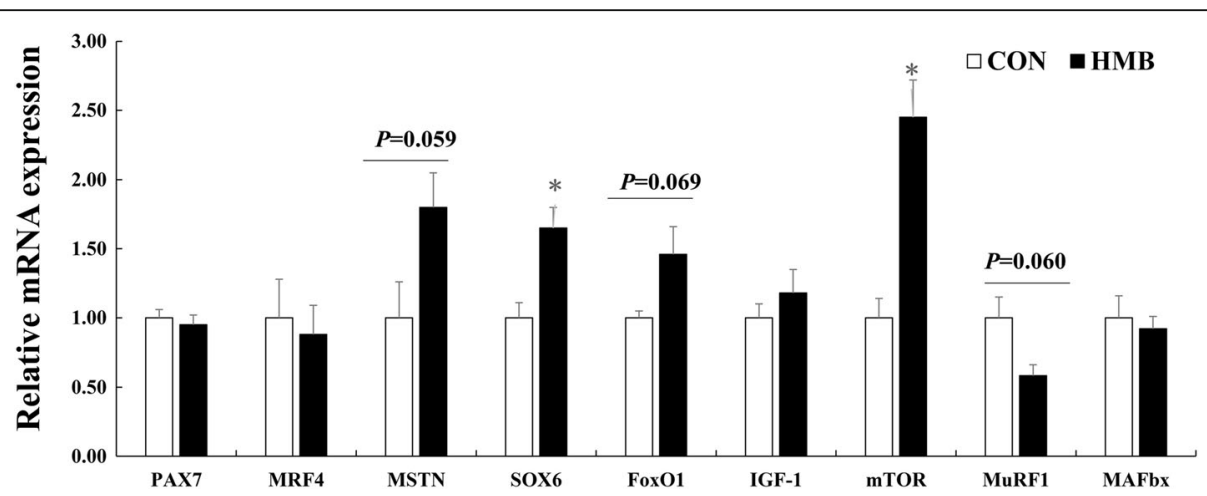

Fig. 2 Effects of feeding HMB to lactating sows on myogenic, protein synthetic and proteolytic gene expressions in skeletal muscle of weaning piglets. Values are means, with their standard errors represented by vertical bars $(n=6)$. ${ }^{*}$ Represents mean values between the two groups differ significantly at $P<0.05$. Data was normalized against GAPDH, with results expressed relative to the CON sample using the $\Delta \Delta C \mathrm{Ct}$ method (where Ct is cycle threshold) with efficiency correction. Pax7 paired box 7; IGF-I insulin-like growth factor-l; mTOR mammalian target of rapamycin; MRF4 muscle regulator factor 4; MSTN myostatin; FoxO1 forkhead box transcription factor O1; MAFbx, muscle atrophy F-box; MuRF1, muscle Ring finger 1; CON control; HMB $\beta$-hydroxy- $\beta$-methylbutyrate 


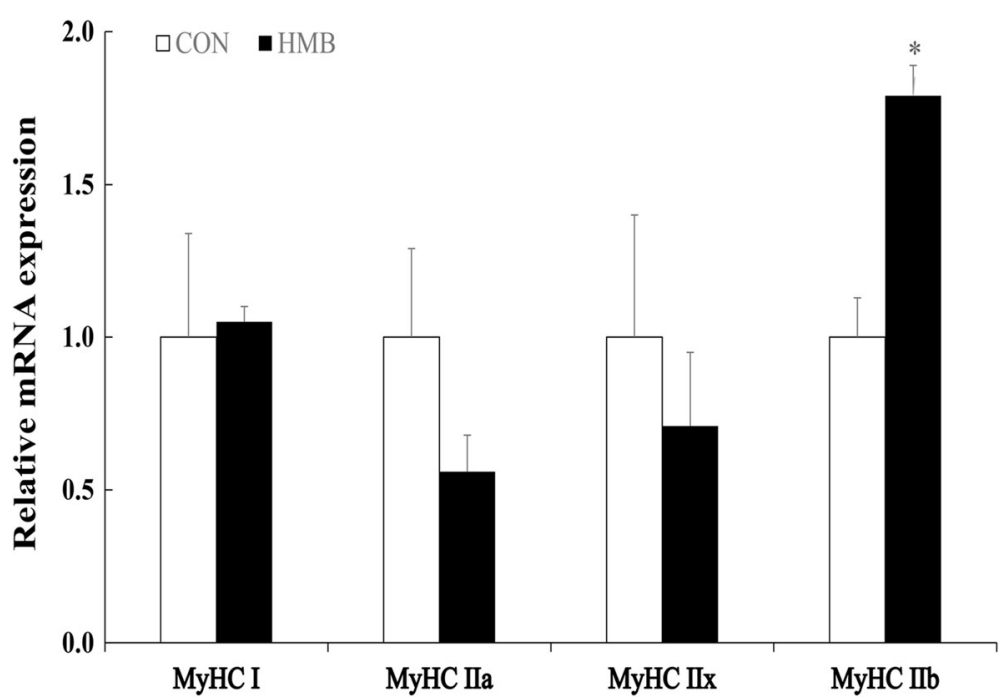

Fig. 3 Effects of supplementing lactating sows with HMB on MyHC isoforms mRNA levels in skeletal muscle of the offspring at $d 28$ of age. Values are means, with their standard errors represented by vertical bars $(n=6) .{ }^{*}$ Represents mean values between the two groups differ significantly at $P<0.05$. Data was normalized against GAPDH, with results expressed relative to the CON sample using the $\Delta \Delta \mathrm{Ct}$ method (where $\mathrm{Ct}$ is cycle threshold) with efficiency correction. MyHC myosin heavy chain; CON control; HMB $\beta$-hydroxy- $\beta$-methylbutyrate

HMB could not lead to the protein degradation of skeletal muscle in piglets in this study. In addition, It is appeared that the rate of $M y H C-I I$ mRNA level is positive to skeletal muscle maturity of piglets [5], in this experiment, maternal HMB treatment significantly increased MyHC-IIb mRNA level and fast-MyHC protein expression in LD of the offspring at weaning. Therefore, supplementation of sows with $\mathrm{HMB}$ during lactation might promote skeletal muscle transformation by transfer of
HMB from maternal milk to skeletal muscle of the offspring during early postnatal period.

The secondary aim of this study was to explore the subsequent performance and skeletal muscle growth of pigs during finishing stage in response to maternal $\mathrm{HMB}$ consumption during lactation. Interestingly, an important observation was that pigs from sows in HMB group had greatly higher finishing BW compared with pigs from sows in the CON group, which was similar with

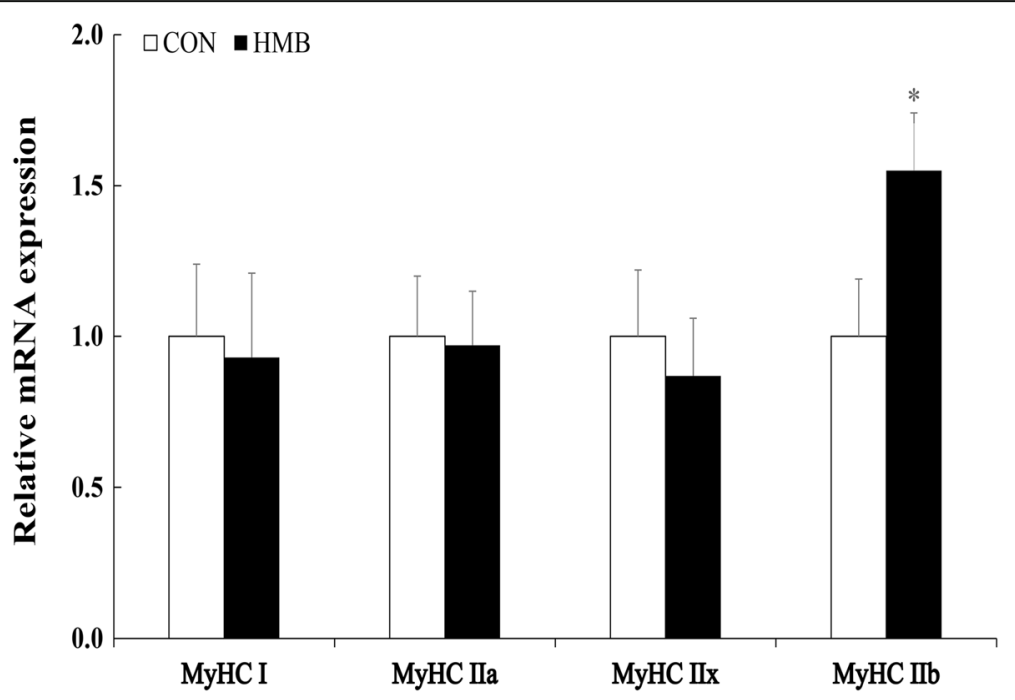

Fig. 4 Effects of feeding HMB to lactating sows on MyHC isoforms mRNA level in skeletal muscle of the offspring at d 180 of age. Values are means, with their standard errors represented by vertical bars $(n=6) .{ }^{*}$ Represents mean values between the two groups differ significantly at $P<0.05$. Data was normalized against GAPDH, with results expressed relative to the control sample using the $\Delta \Delta \mathrm{Ct}$ method (where $\mathrm{Ct}$ is cycle threshold) with efficiency correction. MyHC myosin heavy chain; CON control; HMB $\beta$-hydroxy- $\beta$-methylbutyrate 

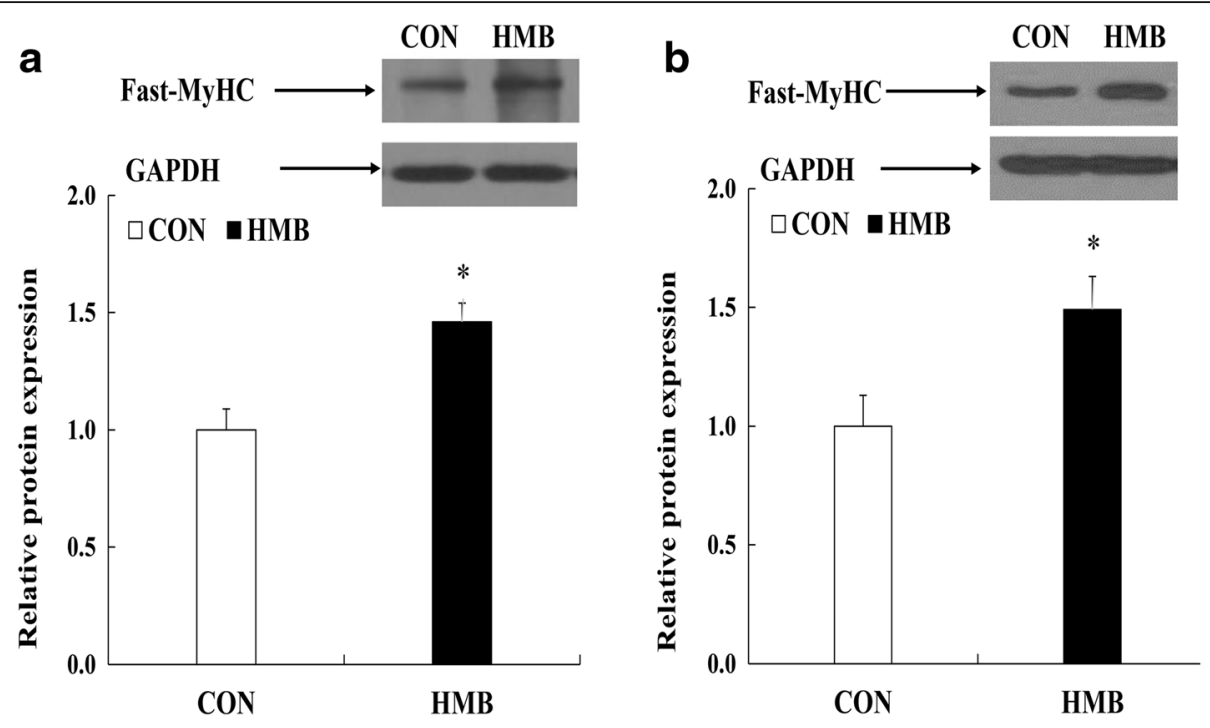

Fig. 5 Effects of feeding HMB to lactating sows on fast-MyHC protein expression in skeletal muscle of the offspring during d 28 and 180 after birth. Values are means, with their standard errors represented by vertical bars $(n=6)$. * Represents mean values between the two groups differ significantly at $P<0.05$. a (the offspring during d 28 after birth); $\mathbf{b}$ (the offspring during d 180 after birth); MyHC myosin heavy chain; GAPDH glyceraldehyde-3-phosphate dehydrogenase. CON control; HMB $\beta$-hydroxy- $\beta$-methylbutyrate

the results of Tatara et al. [28, 29], who showed that when sow supplemented daily with $0.05 \mathrm{~g} / \mathrm{kg}$ BW of HMB-Ca during the last two weeks of gestation, fattening pigs exhibited higher final BW at d 180 of age. Meanwhile, we found no statistical difference in ADFI between treatments from the weaning to $d 180$ after birth. Moreover, we also found that maternal HMB treatment contributed to an elevated carcass weight and lean meat percentage of pigs at d 180 of age. In this respect, a previous study found that feeding HMB to sows during lactation improved the performance of weaning pigs and increased HMB concentration in milk during $\mathrm{d}$ 20 of lactation, which are responsible for the enhanced skeletal muscle development of the offspring [22]. In addition, some studies also showed that pigs with heavier body weights exhibited greater muscle fiber crosssectional areas and /or a greater number of muscle fibers than did pigs with lighter body weights at the same age [30]. A higher mean cross-sectional area of type II fiber was observed in LD of the offspring from sows fed HMB diet during lactation in our study, which also provided the important evidence for the improvement of performance by changing muscle fiber size of pigs. Therefore, it is possible that the increase in muscle fiber size in LD of pigs directly contributes to skeletal muscle growth and performance at d 180 after birth.

In addition, research has suggested that $M y H C-I I b$ is the determining fiber contributing to the differentiation of large and small muscle area in the pig, and high muscularity is positively correlated with a high abundance of $M y H C-I I b$ transcript [31], and more oxidative fibers might convert to glycolytic fibers with increasing age or weight, and that the early developmental stage might be a key stage for this conversion [32]. In this experiment, we found that maternal HMB treatment during lactation greatly increased $M y H C-I I b$ mRNA and fast-MyHC protein levels in LD of the offspring at weaning and finishing stages (Figs. 3, 4, 5), which led to the improved subsequent performance of fattening pigs. Similarly, Rehfeldt et al. [33] reported that high live weight pig had more proportion of fast-twitch glycolytic fiber in semitendinosus muscle compared with low live weight pig by maternal daidzein feeding. Moreover, in this study, higher level of Sox6 mRNA expression was observed in LD of weaning pigs from sows fed HMB diet during lactation. At present, there are few related studies in this respect. But, Wen et al. and Quiat et al. reported that overexpression of Sox 6 down-regulated $M y H C-I$ expression and up-regulated $M y H C-I I b$ expression in pig and mice $[34,35]$. Based on the above results and the previous reports, it is possible that the increased HMB level of skeletal muscle accelerated $M y H C$-IIb isoform transformation of piglets during lactation, which might contribute to skeletal muscle growth during post-weaning stages. Further studies should be conducted in relation to the specific mechanisms of fast-twitch fiber development that are mediated by HMB in piglets.

\section{Conclusion}

In conclusion, the present study showed that HMB supplemented to sows during lactation increases the levels of HMB in maternal milk and skeletal muscle of the 
weaning pigs, which contributes to the $\mathrm{MyHC}-\mathrm{IIb}$ isoform transformation in muscle fiber of piglets at weaning, and subsequent performance of the offspring between $\mathrm{d} 28$ and 180 of age.

\section{Abbreviations}

CSA: Cross-sectional area; FoxO1: Forkhead box transcription factor O1; GAPDH: Glyceraldehyde-3-phosphate dehydrogenase; HMB: $\beta$-hydroxy- $\beta$ methylbutyrate; HMB-Ca: $\beta$-hydroxy- $\beta$-methylbutyrate calcium; IGF-I: Insulinlike growth factor-I; LC-MS/MS: Liquid chromatography with tandem mass spectrometry; LD: Longissimus dorsi; LMA: Loin meat area; MAFbx: Muscle atrophy F-box; MRF4: Muscle regulator factor 4; MSTN: Myostatin; mTOR: Mammalian target of rapamycin; MuRF1: Muscle Ring finger 1; MyHC: Myosin heavy chain; Pax7: Paired box 7

\section{Acknowledgements}

The authors thank their laboratory colleagues for their assistance, and would like to thank John A. Rathmacher and John C. Fuller, Jr for their immeasurable help in determining the purity of HMB-Ca.

\section{Funding}

This work was supported by the National Special Research Fund for Non-Profit Sector (Agriculture) (No.201203015), Academy of Kechuang Feed Industry in Sichuan (2013NZ0056), Research Team of Youth Scientific and Technical Innovation of Sichuan (13CXTD0004), and the Program for Changjiang Scholars and Innovative Research Team in University (IRT13083).

\section{Availability of data and materials}

All data generated or analyzed during this study are included in this published article.

\section{Authors' contributions}

DW designed the study, HW, JZ, CW, RZ, PZ, YS, carried out the study, and HW, SX, BF analyzed the data; HW wrote the paper; DW, LC, ZF, YL, made some modification in the manuscript. All authors read and approved the final manuscript.

\section{Competing interests}

The authors declare that they have no competing interests.

\section{Consent for publication}

Not applicable.

\section{Ethics approval}

All procedure including use and treatment of animals was in accordance with guidelines set by the Animal Care and Use Committee of Sichuan Agricultural University.

Received: 13 July 2016 Accepted: 6 December 2016 Published online: 07 January 2017

\section{References}

1. Brown LD. Endocrine regulation of fetal skeletal muscle growth: impact on future metabolic health. J Endocrinol. 2014;221:R13-29.

2. Bayol SA, Bruce CR, Wadley GD. Growing healthy muscles to optimise metabolic health into adult life. J Dev Org Health Dis. 2014;5:420-34.

3. Lefaucheur L, Gerrard D. Muscle fiber plasticity in farm mammals. J Anim Sci. 2000;77:1-19.

4. Rehfeldt C, Stabenow B, Pfuhl R, Block J, Nurnberg G, Otten W, et al. Effects of limited and excess protein intakes of pregnant gilts on carcass quality and cellular properties of skeletal muscle and subcutaneous adipose tissue in fattening pigs. J Anim Sci. 2012;90:184-96.

5. Lefaucheur L, Ecolan P, Barzic YM, Marion J, Le Dividich J. Early postnatal food intake alters myofiber maturation in pig skeletal muscle. J Nutr. 2003: 133:140-7.

6. Oberbach A, Bossenz Y, Lehmann S, Niebauer J, Adams V, Paschke R, et al. Altered fiber distribution and fiber-specific glycolytic and oxidative enzyme activity in skeletal muscle of patients with type 2 diabetes. Diabetes Care. 2006;29:895-900
7. Gaster M, Staehr P, Beck-Nielsen H, Schrøder HD, Handberg A. GLUT4 is reduced in slow muscle fibers of type 2 diabetic patients is insulin resistance in type 2 diabetes a slow, type 1 fiber disease? Diabetes. 2001;50:1324-9.

8. Conde-Aguilera JA, Lefaucheur L, Tesseraud S, Mercier Y, Le Floc'h N, van Milgen J. Skeletal muscles respond differently when piglets are offered a diet 30\% deficient in total sulfur amino acid for 10 days. Eur J Nutr. 2015;1-10.

9. Boutry C, El-Kadi SW, Suryawan A, Wheatley SM, Orellana RA, Kimball SR, et al. Leucine pulses enhance skeletal muscle protein synthesis during continuous feeding in neonatal pigs. Am J Physiol Endocrinol Metab. 2013; 305:E620-31.

10. Wilkinson DJ, Hossain T, Hill DS, Phillips BE, Crossland H, Williams J, et al. Effects of leucine and its metabolite beta-hydroxy-beta-methylbutyrate on human skeletal muscle protein metabolism. J Physiol. 2013;591:2911-23.

11. Moore DT, Ferket PR, Mozdziak PE. The effect of early nutrition on satellite cell dynamics in the young turkey. Poult Sci. 2005:84:748-56.

12. Kornasio R, Riederer I, Butler-Browne G, Mouly V, Uni Z, Halevy O. Betahydroxy-beta-methylbutyrate (HMB) stimulates myogenic cell proliferation differentiation and survival via the MAPK/ERK and PI3K/Akt pathways. BBAMol Cell Res. 2009;1793:755-63.

13. Alway SE, Pereira SL, Edens NK, Hao Y, Bennett BT. Beta-Hydroxy-betamethylbutyrate (HMB) enhances the proliferation of satellite cells in fast muscles of aged rats during recovery from disuse atrophy. Exp Gerontol. 2013:48:973-84.

14. Wan H, Zhu J, Su G, Liu Y, Hua L, Hu L, et al. Dietary supplementation with $\beta$-hydroxy- $\beta$-methylbutyrate calcium during the early postnatal period accelerates skeletal muscle fibre growth and maturity in intra-uterine growth-retarded and normal-birth-weight piglets. Br J Nutr. 2016;1-10.

15. Cerisuelo A, Baucells MD, Gasa J, Coma J, Carrion D, Chapinal N, et al. Increased sow nutrition during midgestation affects muscle fiber development and meat quality, with no consequences on growth performance. J Anim Sci. 2009;87:729-39.

16. Deshpande P, Jie Z, Subbarayan R, Mamidi VK, Chunduri RH, Das T, et al. Development and validation of LC-MS/MS method for the estimation of beta-hydroxy-beta-methylbutyrate in rat plasma and its application to pharmacokinetic studies. Biomed Chromatogr. 2013;27:142-7.

17. Ehling S, Reddy TM. Investigation of the presence of $\beta$-hydroxy- $\beta$ methylbutyric Acid and a-hydroxyisocaproic acid in bovine whole milk and fermented dairy products by a validated liquid chromatography-mass spectrometry method. J Agric Food Chem. 2014;62:1506-11.

18. Li H, Wan H, Mercier Y, Zhang X, Wu C, Wu X, et al. Changes in plasma amino acid profiles, growth performance and intestinal antioxidant capacity of piglets following increased consumption of methionine as its hydroxy analogue. Br J Nutr. 2014;112:855-67.

19. Guth L, Samaha FJ. Procedure for the histochemical demonstration of actomyosin ATPase. Exp Neurol. 1970;28:365-7.

20. Wang J, Li X, Yang X, Sun Q, Huang R, Xing J, et al. Maternal dietary protein induces opposite myofiber type transition in Meishan pigs at weaning and finishing stages. Meat Sci. 2011;89:221-7.

21. Ramanau A, Kluge H, Spilke J, Eder K. Supplementation of sows with L-carnitine during pregnancy and lactation improves growth of the piglets during the suckling period through increased milk production. J Nutr. 2004;134:86-92

22. Nissen S, Faidley TD, Zimmerman DR, Izard R, Fisher CT. Colostral milk fat percentage and pig performance are enhanced by feeding the leucine metabolite beta-hydroxy-beta-methyl butyrate to sows. J Anim Sci. 1994:72:2331-7.

23. Yonamine C, Teixeira S, Campello R, Gerlinger-Romero F, Rodrigues C, Guimarães-Ferreira $L$, et al. Beta hydroxy beta methylbutyrate supplementation impairs peripheral insulin sensitivity in healthy sedentary Wistar rats. Acta Physiol. 2014;212:62-74

24. Davis TA, Fiorotto ML. Regulation of muscle growth in neonates. Curr Opin Clin Nutr. 2009;12:78.

25. Verstegen MW, Mesu J, van Kempen GJ, Geerse C. Energy balances of lactating sows in relation to feeding level and stage of lactation. J Anim Sci. 1985;60:731-40.

26. van den Brand H, Heetkamp MJ, Soede NM, Schrama JW, Kemp B. Energy balance of lactating primiparous sows as affected by feeding level and dietary energy source. J Anim Sci. 2000;78:1520-8.

27. Kao M, Columbus DA, Suryawan A, Steinhoff-Wagner J, Hernandez-Garcia A, Nguyen $\mathrm{HV}$, et al. Enteral $\beta$-hydroxy- $\beta$-methylbutyrate supplementation increases protein synthesis in skeletal muscle of neonatal pigs. Am J Physiol-Endoc M. 2016;310(11): E1072-84. 
28. Tatara MR, Krupski W, Tymczyna B, Studzinski T. Effects of combined maternal administration with alpha-ketoglutarate (AKG) and beta-hydroxybeta-methylbutyrate (HMB) on prenatal programming of skeletal properties in the offspring. Nutr Metab. 2012:9:39.

29. Tatara MR, Sliwa E, Krupski W. Prenatal programming of skeletal development in the offspring: effects of maternal treatment with betahydroxy-beta-methylbutyrate (HMB) on femur properties in pigs at slaughter age. Bone. 2007;40:1615-22.

30. Rehfeldt C, Tuchscherer A, Hartung M, Kuhn G. A second look at the influence of birth weight on carcass and meat quality in pigs. Meat Sci. 2008:78:170-5.

31. Wimmers K, Ngu N, Jennen D, Tesfaye D, Murani E, Schellander K, et al. Relationship between myosin heavy chain isoform expression and muscling in several diverse pig breeds. J Anim Sci. 2008;86:795-803.

32. Men XM, Deng B, Xu ZW, Tao X, Qi KK. Age-related changes and nutritional regulation of myosin heavy-chain composition in longissimus dorsi of commercial pigs. Animal. 2013;7:1486-92.

33. Rehfeldt C, Adamovic I, Kuhn G. Effects of dietary daidzein supplementation of pregnant sows on carcass and meat quality and skeletal muscle cellularity of the progeny. Meat Sci. 2007;75:103-11.

34. Wen W, Chen X, Chen D, Yu B, Luo J, Huang Z. Cloning and functional characterization of porcine Sox6. Turk J Biol. 2016:40:160-5.

35. Quiat D, Voelker KA, Pei J, Grishin NV, Grange RW, Bassel-Duby R, et al. Concerted regulation of myofiber-specific gene expression and muscle performance by the transcriptional repressor Sox6. Proc Natl Acad Sci U S A. 2011;108:10196-201

\section{Submit your next manuscript to BioMed Central} and we will help you at every step:

- We accept pre-submission inquiries

- Our selector tool helps you to find the most relevant journal

- We provide round the clock customer support

- Convenient online submission

- Thorough peer review

- Inclusion in PubMed and all major indexing services

- Maximum visibility for your research

Submit your manuscript at www.biomedcentral.com/submit

C) Biomed Central 